Bio - grafía. Escritos sobre la Biología y su Enseñanza. ISSN 2027-1034

Edición Extraordinaria. p.p. 485 - 491

Memorias del IX Encuentro Nacional de Experiencias en Enseñanza de la Biología y la Educación Ambiental. IV Congreso Nacional de Investigación en Enseñanza de la Biología.

\title{
¡EL ÚLTIMO ARMADILLO!: LA PÉRDIDA DE LA BIODIVERSIDAD DESDE LA PERSPECTIVA DE ESTUDIANTES RURALES
}

\author{
Andrea del Pilar Sánchez Pinzón ${ }^{1}$
}

\section{RESUMEN}

Esta Biocrónica narra una experiencia de aula con estudiantes rurales de grado sexto de la I.E.D. Novilleros, Caparrapí, Cundinamarca. Esta actividad puede ayudar al desarrollo de habilidades de pensamiento crítico en torno a problemáticas ambientales contextualizadas, ya que vincula diversas áreas del conocimiento como: ciencias naturales, competencias ciudadanas, español, ética y valores. Esta experiencia es un aporte a la construcción de estrategias innovadoras que logren cautivar la sensibilidad de los estudiantes al promover su participación como actores autónomos conscientes de la necesidad de proteger el medio ambiente en el contexto de su realidad.

PALABRAS CLAVE: Pensamiento crítico, juego de roles, educación ambiental, biodiversidad.

\section{INTRODUCCIÓN}

En la actualidad los docentes se ven obligados a enfrentar distintos retos sociales, académicos, disciplinarios y vocacionales, los cuales pueden llevar a cambios en los patrones de comportamiento y a replantear metodologías, lo que se ve influenciado por el contexto en el que se desempeña cada docente. Estos retos o situaciones pueden ser los principales obstáculos para lograr el objetivo de forjar cambios significativos que trasciendan las instituciones educativas y lleguen a la sociedad.

El territorio colombiano es considerado uno de los más biodiversos del planeta, pero ¿qué tanto conocemos, apreciamos y cuidamos esta biodiversidad? ¿Qué papel desempeña la escuela para que los estudiantes, futuros ciudadanos, participen en la protección y cuidado del ambiente? En este sentido los procesos de educación ambiental en Colombia representan un gran desafío para los docentes, ya que más allá de impartir conocimiento, es necesario entender el ambiente como un sistema intrincado en el que todo está interconectado, por tanto se requiere abordar los temas ambientales desde una educación ambiental compleja:

1 Docente de Ciencias Naturales I.E.D. Novilleros Caparrapí Cundinamarca. andreaquimsa@gmail.com 
Bio - grafía. Escritos sobre la Biología y su Enseñanza. ISSN 2027-1034

Edición Extraordinaria. p.p. 485 - 491

Memorias del IX Encuentro Nacional de Experiencias en Enseñanza de la Biología y la Educación Ambiental. IV Congreso Nacional de Investigación en Enseñanza de la Biología.

La educación ambiental compleja es la que forma y capacita para comprender la totalidad que nos rodea y nuestros vínculos con ella, mirándola profunda y ampliamente, analizando y sintetizando, teniendo en cuenta todas las interrelaciones entre sus componentes, considerando su pasado, tratando de predecir el futuro y de modificarlo y respetando las opiniones y posiciones de los otros. (Carrizosa Umaña, 2014 p 266).

En consecuencia las estrategias en educación ambiental deben ser sencillas y atrayentes para que de acuerdo con los diversos escenarios, actores, problemas, soluciones, historias y tiempos, los estudiantes aprendan comportamientos amigables con el medio ambiente y generen habilidades básicas de pensamiento crítico como analizar, comprender, evaluar fuentes, argumentar y proponer, entre otras. (López Aymes, 2016).

\section{Contextualización e identificación del problema ambiental.}

Esta experiencia se desarrolló en un colegio público de la vereda Novilleros en Caparrapí, Cundinamarca. Aunque en esta comunidad priman la agricultura y ganadería, con un alto grado de intervención agrícola y pecuaria, aún coexisten diversas especies silvestres cada vez más escasas, sin olvidar la desaparición de otras que hasta hace algunos años eran comunes en el área. Por tanto el problema ambiental principal es la pérdida de biodiversidad por actividades de caza y destrucción de hábitat.

De acuerdo con lo anterior surge la idea de promover una cultura del cuidado a partir de la contextualización de la problemática ambiental de una forma que genere impacto en los estudiantes, que los haga participes y que los lleve a tomar decisiones proactivamente en bien de su entorno.

\section{Actividades en educación ambiental}

La experiencia se realizó en 4 sesiones:

En la primera sesión se conformaron grupos escogidos al azar, los que una vez definidos dieron lectura a una noticia ficticia ajustada y adaptada al contexto Para este ejemplo se empleó un artículo de diario (El Tiempo, 2017).

\section{¡EXTRA! Indignación por el último armadillo baleado en la vereda Novilleros (Caparrapí, Cundinamarca)}

La noticia ficticia relata cómo un amadillo fue muerto con arma de fuego cerca de las instalaciones del colegio, y además se señala que debido al peligro de extinción de esta especie en particular, el país se encuentra indignado. La noticia finaliza con la siguiente información: 
Bio - grafía. Escritos sobre la Biología y su Enseñanza. ISSN 2027-1034

Edición Extraordinaria. p.p. 485 - 491

Memorias del IX Encuentro Nacional de Experiencias en Enseñanza de la Biología y la

Educación Ambiental. IV Congreso Nacional de Investigación en Enseñanza de la Biología.

"Debido a la gravedad de la situación, se programó una sesión extraordinaria en la que se discutirá el destino de la persona identificada como el agresor y las acciones para reducir los ataques a la fauna amenazada en este municipio. La audiencia se desarrollará el día viernes 5 de mayo a las 9 am en las instalaciones del Colegio Departamental Novilleros y contará con la asistencia de todos los actores involucrados en esta problemática".

Una vez leída la noticia los estudiantes se dividieron y prepararon cada uno de los roles asignados por grupos, de acuerdo a su criterio personal de cómo debe ser el comportamiento del personaje en la situación planteada:

Grupo 1: Alcalde Municipal, Secretario de Ambiente y Secretario de Educación.

Grupo 2: Rector colegio, docente de colegio y estudiante colegio.

Grupo 3: Delegado de la CAR, Comandante de policía y auxiliar de policía.

Grupo 4: Cazador con su esposa e hijo.

Grupo 5: Tres periodistas del diario que publicó la noticia

Grupo 6: Juez, Fiscal y Presidente de la Junta de Acción Comunal.

Grupo 7: Dos ambientalistas y un biólogo.

Al finalizar esta sesión los estudiantes contaron con un tiempo para consultar y profundizar argumentativamente el rol de sus personajes, y además formular las preguntas y respuestas que serían expuestas en la siguiente sesión y las que fueron plasmadas en una cartelera.

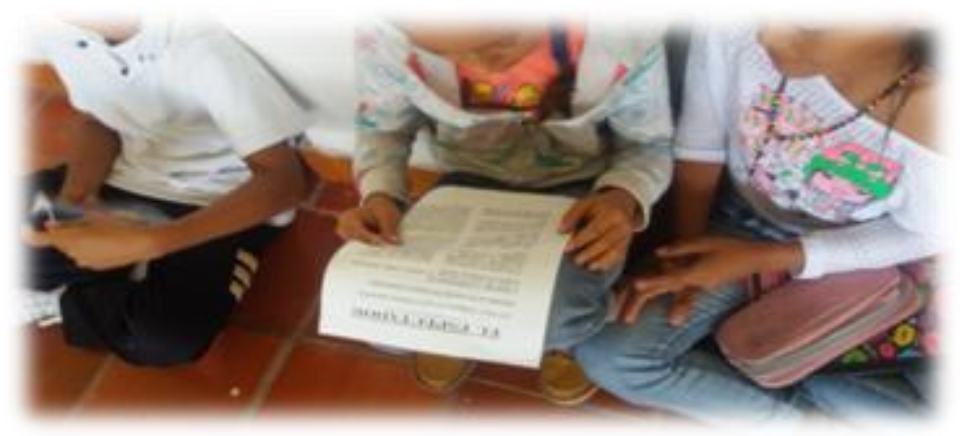

Figura 1. Lectura de la noticia. I.E.D. Novilleros, Caparrapí, Cundinamarca 2017

En la segunda sesión se desarrolló un debate en el que los estudiantes que representaban a los periodistas cuestionaron a los otros personajes, quienes 
Bio - grafía. Escritos sobre la Biología y su Enseñanza. ISSN 2027-1034

Edición Extraordinaria. p.p. 485 - 491

Memorias del IX Encuentro Nacional de Experiencias en Enseñanza de la Biología y la

Educación Ambiental. IV Congreso Nacional de Investigación en Enseñanza de la Biología.

respondieron y preguntaron con base en los argumentos preparados. En este caso fueron los periodistas quienes lideraron la controversia, pero se podría designar a otro, de acuerdo con el desarrollo de la sesión. Por consenso, al final de la discusión los estudiantes elaboraron unas conclusiones y formularon las soluciones pertinentes para esta problemática.

Para la tercera sesión los estudiantes realizaron por grupos un taller con preguntas abiertas tales como: ¿Qué especies han desaparecido o se encuentran en peligro en tu territorio? ¿Qué amenazas crees que enfrentan los animales en tu entorno? ¿Qué acciones puedes realizar para ayudar a estas especies? ¿Cómo puedes sensibilizar a la comunidad para cuidar nuestra biodiversidad? Etcétera. Para contestar estas preguntas los estudiantes contaron con 30 minutos, y en el tiempo restante se socializaron las respuestas.

Por último, durante la cuarta sesión se realizó una clase de ética y valores en la que, mediante un conversatorio, los estudiantes analizaron las actitudes positivas (valores) y actitudes negativas (anti-valores) que ellos consideraban presentadas en la noticia y en el debate realizado. A partir de este dialogo se propuso que escribieran de nuevo y según su perspectiva una noticia, cuento o historieta sobre la historia del armadillo.

\section{RESULTADOS}

La noticia "ficticia" fue un elemento que llamó la atención de los estudiantes, quienes se preguntaron inmediatamente si este hecho en realidad había ocurrido tan cerca de su institución y el por qué ni lo habían notado. Por otra parte, algunos se mostraron afligidos y preocupados por la suerte del armadillo y la del cazador; incluso hubo quienes hicieron conjeturas acerca de quién o quiénes en su comunidad pudieron ser los perpetradores. Así, la contextualización del problema permitió que los estudiantes tuvieran una reacción más real y emotiva al hecho expuesto.

Una vez se aclaró que la nota de prensa no era cierta y que serían ellos los llamados a representar los personajes citados para la audiencia, y que así serían directamente implicados en la problemática, los niños se dispusieron a preparar sus roles de acuerdo al resultado de la aleatorización y la descripción dada. En este sentido, la mayoría de los estudiantes eligió por iniciativa propia indagar con sus docentes, compañeros de otros cursos, familiares y comunidad acerca de los deberes y comportamientos esperados de cada personaje. Además, aquellos que interpretaron al alcalde, al biólogo, a los secretarios del despacho y a los delegados de la CAR optaron por documentarse realizando consultas bibliográficas y por Internet. 
Bio - grafía. Escritos sobre la Biología y su Enseñanza. ISSN 2027-1034

Edición Extraordinaria. p.p. 485 - 491

Memorias del IX Encuentro Nacional de Experiencias en Enseñanza de la Biología y la

Educación Ambiental. IV Congreso Nacional de Investigación en Enseñanza de la Biología.

Gracias a la preparación realizada por los estudiantes se logró conducir un debate interesante ya que cada uno expuso coherentemente sus argumentos. Por ejemplo, el cazador de armadillos explicó las razones económicas que lo llevaron a cometer este "delito", el biólogo presentó a sus compañeros una información extensa de las características e importancia del armadillo, el alcalde se comprometió a crear un "centro de protección animal", y los periodistas orientaron el debate por medio de preguntas a cada uno de los actores, con lo que se promovió la participación de todos los estudiantes.

Al finalizar el debate los estudiantes decidieron que el cazador debía recibir un castigo por su infracción, la cual podía ser una pena privativa de la libertad o trabajo comunitario y/o estudio. Este último hacía referencia a que él también era una víctima ocasionada por la falta de oportunidades y educación. Al final se concluyó que para que esto no siga ocurriendo es necesario que todos los actores participen en campañas de sensibilización.

En cuanto a los resultados del taller de la tercera sesión, los estudiantes determinaron que en su entorno existen otras especies amenazadas como ardillas, zarigüeyas, tortugas, micos y osos hormigueros, entre otras. A este respecto, los niños comentaron que estas especies se encuentran en peligro debido a que algunas destruyen los cultivos o se alimentan de las aves de corral, y otras son tenidas como mascotas 0 simplemente son víctimas de la caza. Por último, a la pregunta ¿qué puedes hacer tú? Los estudiantes respondieron que los animales deben respetarse porque son seres vivos, se debe informar sobre la importancia de cuidar la biodiversidad, al igual que educar a los adultos y denunciar ante las autoridades como la CAR o la policía. Infortunadamente, hubo unos pocos que afirmaron que no podían hacer nada.

Por último en la clase de ética y valores se identificó que en esta situación los valores más recurrentes fueron:

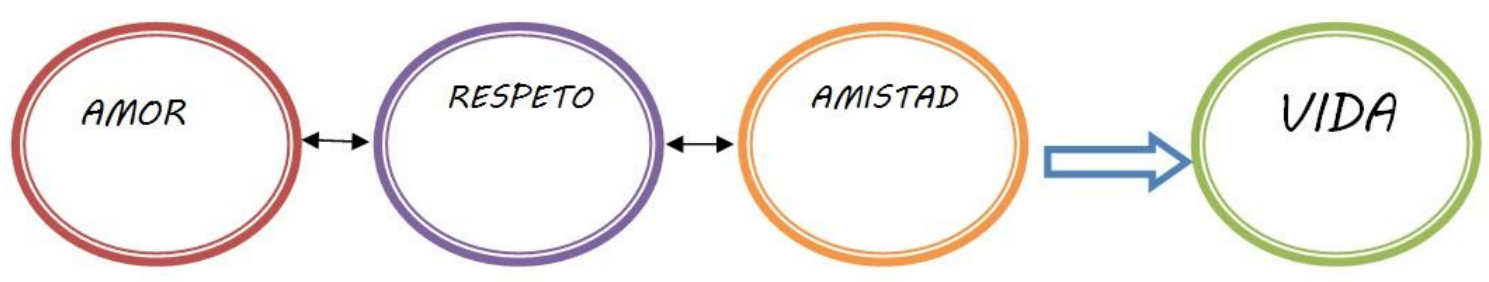

Fig. 2. Valores relevantes 
Bio - grafía. Escritos sobre la Biología y su Enseñanza. ISSN 2027-1034

Edición Extraordinaria. p.p. 485 - 491

Memorias del IX Encuentro Nacional de Experiencias en Enseñanza de la Biología y la Educación Ambiental. IV Congreso Nacional de Investigación en Enseñanza de la Biología.

Como conductas negativas se observaron el maltrato a los animales, la violencia y la deshonestidad.

Al final, con estas reflexiones los estudiantes se orientaron para redactar una nueva historia a través de cuentos, historietas y dibujos.

\section{CONCLUSIONES}

Las actividades realizadas en esta experiencia fueron pertinentes debido a un diseño que no solo permitió que el estudiante aprenda disfrutando y participando, sino también tuvo en cuenta las necesidades y características del contexto, para de esta forma fortalecer sus habilidades de pensamiento como la autonomía y la toma de decisiones.

Además, en este proceso los estudiantes fueron actores principales de su proceso educativo al integrar de forma práctica sus conocimientos y el contenido propuesto relacionándolos con su vida cotidiana y el entorno real. Por lo tanto, los estudiantes fueron los protagonistas en el desarrollo y éxito de la experiencia.

Cabe destacar que este tipo de actividades no solo permiten que se generen dinámicas diferentes en el aula, sino también promueven un impacto en la sociedad por medio de la concientización de los estudiantes, y estos a su vez se convierten en diseminadores actitudinales en su comunidad.

Aunque los contextos pueden variar, puede esperarse que los resultados no tengan grandes cambios debido a que la educación ambiental condiciona unas respuestas aprendidas, pero con esta experiencia de roles la repuesta generada por los niños es fruto de un análisis argumentativo y un debate activo. 
Bio - grafía. Escritos sobre la Biología y su Enseñanza. ISSN 2027-1034

Edición Extraordinaria. p.p. 485 - 491

Memorias del IX Encuentro Nacional de Experiencias en Enseñanza de la Biología y la Educación Ambiental. IV Congreso Nacional de Investigación en Enseñanza de la Biología.

\section{BIBLIOGRAFÍA}

Carrizosa Umaña, J. (2014). Colombia Compleja. Bogotá D.C.: Jardín Botánico de Bogotá José Celestino Mutis.

El Tiempo, R. e. (20 de 03 de 2017). El tiempo. com. Obtenido de http://www.eltiempo.com/vida/medio-ambiente/asesinan-oso-andino-en-cundinamarca69270

Leff, E. (2014). LA APUESTA POR LA VIDA IMAGINACIÓN SOCIOLÓGICA E IMAGINARIOS. México D.F.: VOZES EDITORA. 60.

López Aymes, G. (2016). Pensamiento crítico en el aula. Docencia e Investigación, 41-

Sauvé, L. (2010). Una educación científica y educación ambiental: un cruce fecundo. Enseñanza de las ciencias, 005-018.

Sauvé, L. (2015). La ética ambiental como proyecto de vida y "obra" social: Un. CPU-e, Revista de Investigación, 188-209. 